
Kidney
Blood Pressure
Research

\title{
Identification of Three Novel Frameshift Mutations in the PKD1 Gene in Iranian Families with Autosomal Dominant Polycystic Kidney Disease Using Efficient Targeted Next-Generation Sequencing
}

\author{
Fariba Ranjzad ${ }^{a} \quad$ Nasser Aghdami ${ }^{b} \quad$ Ahmad Tara ${ }^{a} \quad$ Marzieh Mohsenic \\ Reza Moghadasalib,d Abbas Basiria
}

\begin{abstract}
aUrology and Nephrology Research Center, Shahid Beheshti University of Medical Sciences, Tehran, ${ }^{b}$ Department of Stem Cells and Developmental Biology, Cell Science Research Center, Royan Institute for Stem Cell Biology and Technology, ACECR, Tehran, 'Genetics Research Center, University of Social Welfare and Rehabilitation Sciences, Tehran, ${ }^{\mathrm{d} D e p a r t m e n t}$ of Regenerative Biomedicine, Cell Science Research Center, Royan Institute for Stem Cell Biology and Technology, Tehran, Iran
\end{abstract}

\section{Key Words}

Pkd1 • Autosomal dominant polycystic kidney disease $\cdot$ Targeted NGS • Novel mutations

\begin{abstract}
Background/Aims: Autosomal dominant polycystic kidney disease (ADPKD) is one of the most common inherited cystic kidney diseases caused by mutations in two large multi-exon genes, PKD1 and PKD2. High allelic heterogeneity and duplication of $P K D 1$ exons $1-32$ as six pseudo genes on chromosome 16 complicate molecular analysis of this disease. Methods: We applied targeted next-generation sequencing (NGS) in 9 non-consanguineous unrelated Iranian families with ADPKD to identify the genes hosting disease-causing mutations. This approach was confirmed by Sanger sequencing. Results: Here, we determined three different novel frameshift mutations and four previously reported nonsense mutations in the PKD1 gene encoding polycystin 1 in heterozygotes. Conclusion: This study demonstrates the effectiveness of NGS in significantly reducing the cost and time for simultaneous sequence analysis of PKD1 and PKD2, simplifying the genetic diagnostics of ADPKD. Although a probable correlation between the mutation types and phenotypic outcome is possible, however for more extensive studies in future, the consideration of renal hypouricemia (RHUC) and PKD1 coexistence may be helpful. The novel frameshift mutations reported by this study are p. Q1997X, P. D73X and p. V336X.
\end{abstract}




\section{Kidney Blood Pressure Research}

Basiri et al.: Frameshift Mutations in the PKD1 Gene in Iranian ADPKD Families

\section{Introduction}

Autosomal dominant polycystic kidney disease (ADPKD; OMIMs \#173900; 613095) is the most common inherited kidney disease, ultimately leading to end-stage renal disease (ESRD) with an incidence of 1 in 400 to 1 in 1000 [1]. It is characterized by the development and progressive enlargement of cysts in the kidney, typically in late middle age. About $8 \%$ of patients on dialysis or undergoing kidney transplantation have ADPKD. It is a systemic disorder where cysts develop in the kidneys and other areas of the body lead to many clinical manifestations [2].

ADPKD is caused by mutations in two genes, PKD1 and PKD2. PKD1 (MIM\# 601313, 16p13.3) accounts for 85\% of cases and mutation in PKD2 (MIM\#173910, 4q21-22) is responsible for the remainder of the cases (15\%). The phenotype of PKD2 is milder than PKD1 [3]. Both PKD1 and PKD2 exhibit marked allelic heterogeneity, with a high level of gene variations [4]. PKD1 is a complex gene with 46 exons extending to $52 \mathrm{~kb}$ of the genomic DNA that encodes a GC-rich transcript of approximately $14 \mathrm{~kb}$ length, [5] 70\% of its length (exons 1-33) shows six-fold duplication on chromosome $16 \mathrm{p}$ within six pseudo-genes and shares a $97.7 \%$ sequence identity with the un-mutated gene [4, 6-8]. Up to now, more than 2300 mutations of $P K D 1$ have been identified [9]. PKD2 gene consists of 15 exons which encode a $3 \mathrm{~kb}$ open reading frame [10]. More than 300 mutations of PKD2 have been identified. The $P K D 1$ and $P K D 2$ genes encode respectively polycystin-1 and polycystin-2 proteins [11]. Since ADPKD is a dominant disease with high penetrance, the children of affected parents have on average a $50 \%$ chance of developing the disease [12].

ADPKD also shows high level of phenotypic variability in the onset of ESRD with respect to age [13].Three important issues could be considered in ADPKD genotype-phenotype correlation studies: first, ESRD occurs averagely about 20 years earlier in ADPKD patients with PKD1 than those with PKD2 [13]. Second, the position of the mutation in PKD1 gene is associated with ESRD onset with respect to age [14]. Third, mutation type in PKD1 gene, regardless to mutation position, correlate with renal survival [13].

There is a general consensus that ADPKD could routinely be diagnosed by renal imaging, using age-dependent cyst number criteria determined by ultrasound [15]. Computed tomography (CT) and magnetic resonance imaging (MRI) can also quantify renal cystic disease, they are not very effective at diagnosing ADPKD in young individuals and in patients with mild symptoms caused by PKD2 mutations. ADPKD is not clinically detectable throughout the first few decades of life (age, $<30$ years) [16]. The high allelic heterogeneity of $A D P K D$ genes with six pseudo-genes at the $5^{\prime}$ end of the PKD1 gene, elongated in twothirds of the gene, make molecular diagnostics problematic [17].

The requirement for a relatively large family and multiple diagnosed members are limiting factors for genetic diagnosis of $A D P K D$ by linkage analysis [18]. The high cost and time required for PKD1 and PKD2 mutation analysis using Sanger sequencing technique limit its extensive utilization in the clinical setting. It requires laborious long-range amplifications [12]. Next generation sequencing (NGS) of PKD1 and PKD2 genes have been tried for ADPKD diagnosis [19-21] and using this technique routine genetic diagnostics of ADPKD and a significant reduction in the time and cost could be achieved for simultaneous sequence analysis of ADPKD genes [22]. Despite the abundance of families with ADPKD in the Asian population [23],there are very few published reports in the literature. In this communication, we report the study of PKD1 and PKD2 in nine Iranian unrelated ADPKD families using targeted NGS.

\section{Materials and Methods}

Ethical compliance

The study was approved by the local ethics committees, in adherence to thedeclaration of Helsinki, and informed consent was obtained from all the patients concerned before their participation in this study. 


\section{Kidney Blood Pressure Research}

Basiri et al.: Frameshift Mutations in the PKD1 Gene in Iranian ADPKD Families

Table 1. Clinical characteristics of ADPKD probands, Abbreviations: CKD 5 T, Chronic Kidney Disease, stage 5 treated by renal transplantation; ESRD, end-stage renal disease. Abbreviations: CKD 5 T, Chronic Kidney Disease, stage 5 treated by renal transplantation; ESRD, end-stage renal disease

\begin{tabular}{cccccc}
\hline Patient code & Gender & Age/age at diagnosis, years & Family history & ESRD & Extrarenal cysts \\
\hline PKD01-1 & Female & $28 / 17$ & + & No & No \\
PKD 03-1 & Female & $17 / 17$ & + & No & Yes \\
PKD 04-2 & Male & $25 / 25$ & + & No & Yes \\
PKD 06-3 & Male & $51 / 25$ & + & No & No \\
PKD 09-1 & Male & $24 / 20$ & + & CKD 5T (ESRD) & No \\
PKD 011-1 & Male & $46 / 25$ & + & CKD 5T (ESRD) & No \\
PKD 013-1 & Male & $40 / 24$ & + & CKD 5T (ESRD) & Yes \\
PKD 015-2 & Male & $31 / 16$ & + & No & Yes \\
PKD 016-2 & Male & $18 / 16$ & & & \\
\hline
\end{tabular}

\section{Subject data}

Nine unrelated ADPKD probands (seven males and two females) showing classical dominant pattern of inheritance were recruited for the study from dialysis centers and nephrology clinics in Tehran, Iran. The diagnosis of ADPKD in the selected probands was established by Pei's ultrasound diagnostic criteria [24]. The probands had one affected parent with ADPKD and all of them had at least one member with a more serious manifestation of the disease (ESRD before 50 years of age) or they had already had developed ESRD. All the probands selected had not gone through mutational screening. Asymptomatic at-risk individuals were examined by ultrasound. Pedigrees were generated using the family information from probands. Total genomic DNA from available family members was extracted from blood samples using a standard phenol-chloroform procedure. The quality and quantification of DNA samples were appraised using spectrophotometry and 1\% agarose gel electrophoresis, respectively. Some clinical characteristics of the 9 ADPKD patients studied are summarized in Table 1.

\section{Targeted Next Generation Sequencing data analysis}

Targeted NGS experiments were performed by BGI. The designed custom solution-based capture array hybridization (NimbleGen, Roche) was applied for capture. Image analysis, error estimation and base calling were performed via Illumina Pipeline for raw data generation by BGI. Indexed primers were used to determine the reads from different samples. The 90 bp clean reads obtained were then aligned using Burrows Wheeler Aligner (BWA) software with human reference genome from the NCBI database (Build 37). Here, the applied NCBI RefSeq sequences were NG_008617.1 and NM_001009944.2 for PKD1 and NG_008604 and NM_000297.3 for PKD2. SNPs and insertion-deletions (indels) were identified with SOAPsnp software and the Genome Analysis Toolkit (GATK) [21].

\section{Sanger sequencing}

To validate the variations identified by NGS, the corresponding gene regions surrounding the variations were amplified by long-range polymerase chain reaction (LR-PCR) according to previously reported PKD1-specific primers [25]. PCR products were purified from agarose gel slices with the Fermentas kit (ThermoFisher Scientific, Rockford, IL, USA) and sequenced by Sanger sequencing using appropriate reported internal primers and the manufacturer's protocol (Table 2).

\section{Bioinformatics analysis and mutation identification and classification}

For confirmation of candidate mutations against electronic database information and computational analysis, the detected sequence variations within our study were checked with the currently published list of PKD gene variants in the Human Gene Mutation Database (HGMD) [26] and Autosomal Dominant Polycystic Kidney Disease Mutation Database (PKDB) [27]. To evaluate the effects of novel variations, they were analyzed by a web-based computational pathogenicity prediction tool which included Mutation Taster [28].

\section{Segregation analysis}

To confirm the association between mutation and the pathogenicity of the disease, careful analysis of other available patients in the pedigree was carried out by direct sequencing. Meanwhile, unaffected fam- 


\section{Kidney Blood Pressure Research}

ily members and normal controls from the Iranian normal population database were also checked for the mutation to confirm the prediction.

\section{Results}

We performed mutational analysis of ADPKD genes in the nine unrelated Iranian ADPKD families. Using targeted NGS, three frameshift deletion mutations and four nonsense mutations in nine families were detected in our set of ADPKD probands (Table 3). All were heterozygotes. We did not detect any aberrant variants in PKD2 gene. Detected frameshift mutations had not been reported previously in any published database including exome variant server (pub-
Table 2. PKD1 sequencing primers

\begin{tabular}{ccc}
\hline Primer name & Sequence & Related proband / Reference \\
\hline 15R11 & 5'-TGAAGTCACCTGTGCTGTTGT-3' & $01[30]$ \\
15 F12 & 5'-CGTGAACAGGGCGCATTA-3' & \\
15F12 & 5'-CGTGAACAGGGCGCATTA-3' & \\
15 F13 & 5'-CTGGAGGTGCTGCGCGTT-3' & $03[30]$ \\
15F14 & 5'-GCCCCCGTGGTGGTCAGC-3' & \\
15F1 & 5'-GTCGCCAGGGCAGGACACAG-3' & $04[30]$ \\
15F4 & 5'-CAGCAGCAAGGTGGTGGC-3' & $06[30]$ \\
7F & 5'-GGAGTGCCCTGAGCCCCCT-3' & $09[25]$ \\
2F & 5'-TTGGGGATGCTGGCAATGTG-3' & $011[25]$ \\
2R & 5'-GGGATTCGGCAAAGCTGATG-3' & \\
5F3 & 5'-CCGAGGTGGATGCCGCTG-3' & $013[25]$ \\
5R3 & 5'-GAAGGGGAGTGGGCAGCAGAC-3 & \\
34F & 5'-GCCCACCCTATGCCTCCTG-3' & $015[31]$ \\
34R & 5'-GGGTGGGCTGTGTGTGTGAC-3' & \\
33F & 5'-GGGTGGGCTGTGTGTGTGAC-3' & $016[31]$ \\
\hline
\end{tabular}

Table 3. Novel pathogenic mutations identified in PKD1 gene in patients with ADPKD

\begin{tabular}{|c|c|c|c|c|c|c|c|}
\hline Proband & $\begin{array}{c}\text { Nucleic acid } \\
\text { change }\end{array}$ & $\begin{array}{c}\text { Amino acid } \\
\text { change }\end{array}$ & Exon & Consequence & $\begin{array}{l}\text { Mutation Taster } \\
\text { prediction }\end{array}$ & $\begin{array}{c}\text { Clinical } \\
\text { significance }\end{array}$ & $\begin{array}{c}\text { Co- } \\
\text { segregate }\end{array}$ \\
\hline PKD 01 & $\mathrm{C} 4306 \mathrm{~T}$ & R1436X & 15 & Stop gain & Disease causing & $\begin{array}{l}\text { Definitely } \\
\text { pathogenic }\end{array}$ & Yes \\
\hline PKD 03 & C4306T & R1436X & 15 & Stop gain & Disease causing & $\begin{array}{l}\text { Definitely } \\
\text { pathogenic }\end{array}$ & Yes \\
\hline PKD 04 & C6406T & Q2136X & 15 & Stop gain & Disease causing & $\begin{array}{l}\text { Definitely } \\
\text { pathogenic }\end{array}$ & Yes \\
\hline PKD 06 & 5991delG & Q1997fs & 15 & Frameshift & Disease causing & $\begin{array}{l}\text { Definitely } \\
\text { pathogenic }\end{array}$ & Yes \\
\hline PKD 09 & C1597T & Q533X & 7 & Stop gain & Disease causing & $\begin{array}{l}\text { Definitely } \\
\text { pathogenic }\end{array}$ & Yes \\
\hline $\begin{array}{r}\text { PKD } \\
011\end{array}$ & 217_218del & D73fs & 2 & Frameshift & Disease causing & $\begin{array}{l}\text { Definitely } \\
\text { pathogenic }\end{array}$ & $\begin{array}{c}\text { Not } \\
\text { available }\end{array}$ \\
\hline $\begin{array}{l}\text { PKD } \\
013\end{array}$ & 1007_1020del & V336fs & 5 & Frameshift & Disease causing & $\begin{array}{c}\text { Definitely } \\
\text { pathogenic }\end{array}$ & $\begin{array}{c}\text { Not } \\
\text { available }\end{array}$ \\
\hline $\begin{array}{l}\text { PKD } \\
015\end{array}$ & $\mathrm{C} 10420 \mathrm{~T}$ & Q3474X & 34 & Stop gain & Disease causing & $\begin{array}{c}\text { Definitely } \\
\text { pathogenic }\end{array}$ & Yes \\
\hline $\begin{array}{r}\text { PKD } \\
016\end{array}$ & $\mathrm{C} 10420 \mathrm{~T}$ & Q3474X & 34 & Stop gain & Disease causing & $\begin{array}{l}\text { Definitely } \\
\text { pathogenic }\end{array}$ & Yes \\
\hline
\end{tabular}

licly available; http://evs.gs.washington.edu/EVS/), ADPKD mutation (PKDB; http://pkdb. mayo.edu) and NCBI dbSNP databases. They have been determined as novel and validated using classic Sanger sequencing.

Mutation taster software was used to assess the pathogenicity of novel variations, and it recognized all of them as disease-causing mutations. Each candidate mutation was assessed for its co-segregation with disease in the relevant available family members, at least one normal (aged, > 30 years individuals) and one available affected member. The mutations were identified in all affected members and were absent in asymptomatic family members and in 400 normal members (Iranian population).This provides evidence for causative pathogenic mutations.

\section{Mutations detection}

All detected variants were catagorised as frameshift and nonsense mutations, predicting an early stop codon (Table 3). The frameshift mutations p. Q1997X, P. D73X and p. V336X were detected in patients PKD06, PKD 011 and PKD013, respectively (Fig. 1).The nonsense mutation p.Q3475X in exon 34 of the PKD1 gene was found in two unrelated Iranian patients (PKD015 and PKD016) and the nonsense mutation p.R1436X in exon 15 was found in another two unrelated Iranian patients (PKD01 and PKD03) .Mutations p.Q2136X in exon 15 and p.Q533X in exon 7 were detected in patients PKD04 and PKD09, respectively 


\section{Kidney \\ Blood Pressure \\ Research}

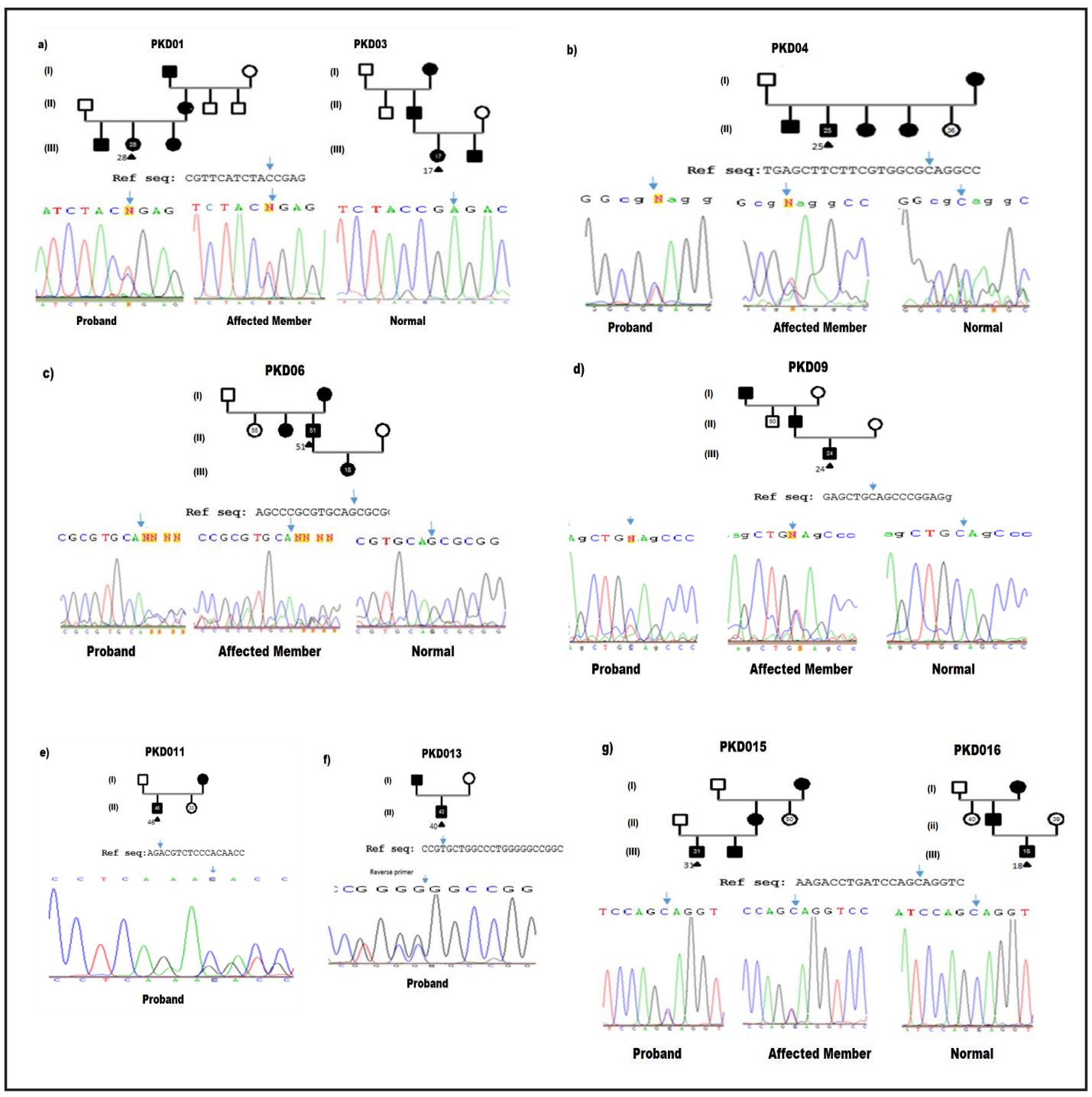

Fig. 1. The 3 novel frameshift and previously reported nonsense mutations in PKD1 gene were identified by DNA sequencing and the partial sequence at the related location in the affected member and wild-type gene. (a) Transition of a C>T at nucleotide 4306 in exon 15 of the PKD1 gene resulted in a premature stop codon, which might stop the transcription and lead to truncation of polycystin-1 in families PKD01 and PKD03; (b) transition of a C>T in exon 15 at nucleotide 6406 leading to a stop codon in family PKD04; (c) deletion of G at nucleotide 5991 in exon 15 causing a frameshift of the reading frame in family PKD06; (d) transition of a C>T at nucleotide 1597 in exon 7 leading to a stop codon in family PKD09; (e)2 bp deletion at nucleotide 217-218 in exon 2 causing a frameshift of the reading frame in family PKD011; (f) a 14 bp deletion from nucleotide 1007 to 1020 in exon 5 causing a frameshift of the reading frame in family PKD013; (g) transition of a C>T in exon 34 at nucleotide 10420 leading to a stop codon in families PKD015 and PKD016.

\section{Discussion}

In Iran, ADPKD is the most common inherited kidney disease, affecting more than 200,000 Iranians. The study of PKD1 and PKD2 gene mutations in Iranian patients contribute to the data of genetic diversity between diverse ethnic groups and further upgrade the 


\section{Kidney Blood Pressure Research}

Kidney Blood Press Res 2018;43:471-478

\begin{tabular}{l|l}
\hline DOI: $10.1159 / 000488471$ & (C) 2018 The Author(s). Published by S. Karger AG, Basel
\end{tabular}

Published online: March 27, 2018

www.karger.com/kb

476

mutation database of the world population. A plethora of mutations in PKD1 and PKD2 genes have been reported, including frameshift, nonsense, splice-site, missense, small insertion-deletion and large deletion/duplication rearrangements. In spite of the wide range of existing disease-causing variants in ADPKD genes, the investigations of Iranian patients with ADPKD are rather limited and very few reported mutations have been found in the studies of Iranian ADPKD families. To the best of our knowledge, this is the first significant study of ADPKD gene mutations in the Iranian ADPKD families by targeted NGS as efficient method for detection of ADPKD. The NGS method used in this study has the potential to greatly improve genetic testing for ADPKD genes by allowing simultaneous detection of copy number variations and point mutations via a single test. Accordingly, this method may increase the rate of mutation detection and hence significantly decrease testing turnaround time and costs.

In this study, we studied nine unrelated Iranian families with ADPKD. We identified three novel frameshift mutations and four previously reported nonsense mutations in PKD1 gene in all selected ADPKD families (Fig. 1). The total mutation detection rate was $100 \%$. The mutations in all patients were well distributed over the length of the replicated region. The mutations spread throughout the 5' region of the PKD1 gene. Two nonsense mutations, p.R1436X and p.Q3474X, each were present in two unrelated Iranian patients with similar clinical course (families 01, 03 and 015, 016, respectively), which may be related to having a common ancestor. All of detected variants were novel deletion frameshift and previously reported nonsense mutations in PKD1 gene and predicted to truncate the coding sequence by introducing premature termination codons. The functional impact of the detected variants was predicted as deleterious by Mutation Taster software. The variants were cosegregated with ADPKD in the available family members. They were absent in unaffected family members and 400 normal Iranians. The identified frameshift mutations were absent in any published database including HGMD, ADPKD and NCBI dbSNP databases. They have been determined as novel. The overall evidences supported the detected mutations as a pathogenic mutation for ADPKD. The bioinformatics analysis concluded the variants as definitely pathogenic mutations.

ADPKD shows a high degree of phenotypic variability between patients due to genetic and allelic heterogeneity. Truncating PKD1 mutations are associated with ESRD onset at younger age than nontruncating mutations [29]. Consistent with these studies, the probands in our study had at least one family member with early-onset ESRD or they were already diagnosed with ESRD and were younger than 50 years of age. All mutations found within our study were truncated nonsense and frameshift mutations. This cohort confirms a probable correlation between the mutation types and phenotypic outcome is possible in some way. Therefore, the age of onset of end-stage renal failure can be influenced by the causal mutation.

In contrast to our study, a previous study reported that its the position and not the type of PKD1 mutation that correlates with the severity of renal disease in ADPKD patients. They found no significant differences among patients with missense, in-frame changes and truncating mutations in PKD1 gene [14]. Thus further studies in larger Iranian ADPKD patient groups and follow-up in other young affected family members are necessary to verify the reported association.

\section{Conclusion}

It can be concluded that, although this study added 3 novel mutations p. Q1997X, P. D73X and p. V336X to the spectrum of PKD1 gene mutations, the majority of mutation types of the PKD1 gene in the Iranian population may as yet be undiscovered. Also, coexistence of RHUC type I and ADPKD have been reported [32], there isn't any study about RHUC in Iranian population. This study may be useful to design more extensive investigations with consideration of the coexistence of RHUC and PKD1 and help the improvement of molecular and functional analyses of ADPKD in Iranian patients by enriching our knowledge of the genotype-phenotype correlations of ADPKD. Finally, the use of NGS method in the molecular 


\section{Kidney Bloód Pressure Research}

diagnosis of ADPKD will increase the number of studied families and expand the mutation database of ADPKD.

\section{Acknowledgements}

We are deeply grateful to the families who took part in this research and we profoundly appreciate their collaboration which made this study possible. This work was supported by the Royan Institute and the Urology and Nephrology Research Center (UNRC) of Shahid Beheshti University of Medical Sciences.

\section{Disclosure Statement}

The authors declared that they have no conflict of interest.

\section{References}

-1 Liu B, Chen SC, Yang YM, Yan K, Qian YQ Zhang JY, Hu YT, Dong MY, Jin F, Huang HF, Xu CM: Identification of novel PKD1 and PKD2 mutations in a Chinese population with autosomal dominant polycystic kidney disease. Sci Rep 2015;5:17468-17468.

2 Peces R, Venegas JL: Seminal vesicle cysts and infertility in autosomal dominant polycystic kidney disease. Nefrologia 2004;25:78-80.

-3 George JW, Dille EA, Heckert LL: Current concepts of follicle-stimulating hormone receptor gene regulation. Biol Reprod 2010;84:7-17.

4 Cornec-Le Gall E, Audrézet MP, Le Meur Y, Chen JM, Férec C: Genetics and pathogenesis of autosomal dominant polycystic kidney disease: 20 years on. Hum Mutat 2014;35:1393-1406.

5 Germino GG, Weinstat-Saslow D, Himmelbauer H, Gillespie GA, Somlo S, Wirth B, Barton N, Harris KL, Frischauf AM, Reeders ST: The gene for autosomal dominant polycystic kidney disease lies in a 750-kb CpGrich region. Genomics 1992;13:144-151.

-6 European Polycystic Kidney Disease Consortium: The polycystic kidney disease 1 gene encodes a $14 \mathrm{~kb}$ transcript and lies within a duplicated region on chromosome 16. Cell 1994;77:881-894.

-7 International Polycystic Kidney Disease Consortium: Polycystic kidney disease: the complete structure of the PKD1 gene and its protein. Cell 1995;81:289-298.

$>8$ Bogdanova N, Markoff A, Gerke V, McCluskey M, Horst J, Dworniczak B: Homologues to the first gene for autosomal dominant polycystic kidney disease are pseudogenes. Genomics 2001;74:333-341.

-9 Felson DT: Comparing the prevalence of rheumatic diseases in China with the rest of the world. Arthritis Res Ther 2008;10:106.

10 Pei YO, He N, Wang KA, Kasenda M, Paterson AD, Chan GA, Liang Y, Roscoe J, Brissenden J, Hefferton D, Parfrey P: A spectrum of mutations in the polycystic kidney disease-2 (PKD2) gene from eight Canadian kindreds. J Am Soc Nephrol 1998;9:1853-1860.

11 Mekahli D, Parys JB, Bultynck G, Missiaen L, De Smedt H: Polycystins and cellular Ca2+ signaling. Cell Mol Life Sci. 2013;70:2697-2712.

12 Tan AY, Michaeel A, Liu G, Elemento O, Blumenfeld J, Donahue S, Parker T, Levine D, Rennert H: Molecular diagnosis of autosomal dominant polycystic kidney disease using next-generation sequencing. J Mol Diagn 2014;16:216-228.

13 Cornec-Le Gall E, Audrézet MP, Chen JM, Hourmant M, Morin MP, Perrichot R, Charasse C, Whebe B, Renaudineau E, Jousset P, Guillodo MP: Type of PKD1 mutation influences renal outcome in ADPKD. J Am Soc Nephrol 2013;24:1006-1013.

14 Rossetti S, Burton S, Strmecki L, Pond GR, San Millán JL, Zerres K, Barratt TM, Ozen S, Torres VE, Bergstralh EJ, Winearls CG: The position of the polycystic kidney disease 1 (PKD1) gene mutation correlates with the severity of renal disease. J Am Soc Nephrol 2002;13:1230-1237. 


\section{Kidney \\ Blood Pressure Research}

\begin{tabular}{l}
\hline Kidney Blood Press Res 2018;43:471-478 \\
\begin{tabular}{l|l} 
DOI: 10.1159/000488471 & $\begin{array}{l}\text { @ } 2018 \text { The Author(s). Published by S. Karger AG, Basel } \\
\text { www.karger.com/kbr }\end{array}$ \\
Published online: March 27, 2018
\end{tabular}
\end{tabular}

Basiri et al.: Frameshift Mutations in the PKD1 Gene in Iranian ADPKD Families

15 Kapoor S, Rodriguez D, Mitchell K, Wüthrich RP: High Resolution Ultrasonography for Assessment of Renal Cysts in the PCK Rat Model of Autosomal Recessive Polycystic Kidney Disease. Kidney Blood Press Res 2016;41:186-196.

-16 Huang E, Samaniego-Picota M, McCune T, Melancon JK, Montgomery RA, Ugarte R, Kraus E, Womer K, Rabb H, Watnick T: DNA testing for live kidney donors at risk for autosomal dominant polycystic kidney disease. Transplantation. 2009;87:133.

-17 Tan YC, Blumenfeld JD, Anghel R, Donahue S, Belenkaya R, Balina M, Parker T, Levine D, Leonard DG, Rennert H: Novel method for genomic analysis of PKD1 and PKD2 mutations in autosomal dominant polycystic kidney disease. Hum Mutat 2009;30:264-273.

-18 Pei Y, Watnick T: Diagnosis and screening of autosomal dominant polycystic kidney disease. Adv Chronic Kidney Dis 2010;17:140-152.

19 Rossetti S, Hopp K, Sikkink RA, Sundsbak JL, Lee YK, Kubly V, Eckloff BW, Ward CJ, Winearls CG, Torres VE, Harris PC: Identification of gene mutations in autosomal dominant polycystic kidney disease through targeted resequencing. J Am Soc Nephrol 2012;23:915-933.

20 Trujillano D, Bullich G, Ossowski S, Ballarín J, Torra R, Estivill X, Ars E: Diagnosis of autosomal dominant polycystic kidney disease using efficient PKD1 and PKD2 targeted next-generation sequencing. Mol Genet Genomic Med 2014;25:412-421.

-21 Yang T, Meng Y, Wei X, Shen J, Zhang M, Qi C, Wang C, Liu J, Ma M, Huang S: Identification of novel mutations of PKD1 gene in Chinese patients with autosomal dominant polycystic kidney disease by targeted nextgeneration sequencing. Clin Chim Acta 2014;433:12-19.

22 Qi XP, Du ZF, Ma JM, Chen XL, Zhang Q, Fei J, Wei XM, Chen D, Ke HP, Liu XZ, Li F: Genetic diagnosis of autosomal dominant polycystic kidney disease by targeted capture and next-generation sequencing: utility and limitations. Gene 2013;516:93-100.

23 Phakdeekitcharoen B, Watnick TJ, Ahn C, Whang DY, Burkhart B, Germino GG: Thirteen novel mutations of the replicated region of PKD1 in an Asian population. Kidney Int 2000;58:1400-1412.

24 Pei Y, Obaji J, Dupuis A, Paterson AD, Magistroni R, Dicks E, Parfrey P, Cramer B, Coto E, Torra R, San Millan JL: Unified criteria for ultrasonographic diagnosis of ADPKD. J Am Soc Nephrol 2009;20:205-212.

25 Phakdeekitcharoen B, Watnick TJ, Germino GG: Mutation analysis of the entire replicated portion of PKD1 using genomic DNA samples. J Am Soc Nephrol 2001;12:955-963.

26 Stenson PD, Mort M, Ball EV, Howells K, Phillips AD, Thomas NS, Cooper DN: The human gene mutation database: 2008 update. Genome Med 2009;1:13.

-27 Gout AM, Martin NC, Brown AF, Ravine D: PKDB: Polycystic Kidney Disease Mutation Database-a gene variant database for autosomal dominant polycystic kidney disease. Hum Mutat 2007;28:654-659.

-28 Schwarz JM, Cooper DN, Schuelke M, Seelow D: MutationTaster2: mutation prediction for the deepsequencing age. Nat Methods 2014;11:361-362.

-29 Harris PC, Hopp K: The mutation, a key determinant of phenotype in ADPKD. J Am Soc Nephrol 2013;24:868-870.

30 Watnick T, Phakdeekitcharoen B, Johnson A, Gandolph M, Wang M, Briefel G, Klinger KW, Kimberling W, Gabow P, Germino GG: Mutation detection of PKD1 identifies a novel mutation common to three families with aneurysms and/or very-early-onset disease. Am J Hum Genet 1999;65:1561-1571.

31 Rossetti S, Chauveau D, Walker D, Saggar-Malik A, Winearls CG, Torres VE, Harris PC: A complete mutation screen of the ADPKD genes by DHPLC. Kidney Int 2002;61:1588-1599.

32 Stiburkova B, Stekrova J, Nakamura M, Ichida K: Hereditary renal hypouricemia type 1 and autosomal dominant polycystic kidney disease. Am J Med Sci 2015;350:268-271. 